\title{
Pursuance of Skim Milk Containing Prebiotics on Survival and Activity of Probiotics Lactobacilli Bacteria
}

\author{
A.S. Chungada ", K.G. Deshpande and R.A. Thakre \\ MGM College of Agricultural Biotechnology, Aurangabad, Marathwada Krishi Vidyapeeth, \\ Parbhani, Maharashtra, India \\ *Corresponding author
}

\begin{tabular}{|l|}
\hline K e y w o r d s \\
$\begin{array}{l}\text { Lactobacillus, Gastric, } \\
\text { probiotics, Prebiotics, } \\
\text { Viability, Acidic }\end{array}$ \\
\hline Article Info \\
\hline $\begin{array}{l}\text { Accepted: } \\
\text { 12 October } 2018 \\
\text { Available Online: } \\
10 \text { November } 2018\end{array}$ \\
\hline
\end{tabular}

\section{A B S T R A C T}

Present investigation was undertaken to explore the potential of skim milk containing prebiotics maize and oat on probiotics Lactobacilli to enhance their survival and activity. The experiment was laid out in completely randomized design with twenty one treatments and three replication. The Lactobacilli casei was isolated from curd and considered to be LAB based on their gram-positive and catalase-negative morphology. Maize flour and oat bran prebiotics were added into the culture of Lactobacilli, the prebiotics gets fermented due to Lactobacilli. The cell viability of Lactobacilli was tested by exposing it to stimulated gastric juice for various time periods, all the Lactobacilli sample was able to grow in stimulated gastric juice for various time periods. Among the two prebiotics used, the Lactobacilli grown with maize showed significant viability with higher number of colonies as compare to oat. Bacteria survived were counted by pour plate technique. The results revealed that, Lactobacilli were able to grow and remain viable in the presence of highly acidic condition which is the regular environment in the intestine. Thus we can enhance the probiotics activity of Lactobacilli casei with the addition of prebiotics such as oat and maize. The best results regarding probiotics functionality and stability were obtained by adding $5 \%$ and $9 \%$ oat bran or buckwheat flour, respectively in fermentative medium.

\section{Introduction}

Lactobacilli are typically characterized as gram-positive, non-spore-forming, non-motile, catalase negative bacteria growing under micro aerobic or strictly anaerobic conditions. Some species produce lactic and acetic acids when they use glucose as a carbon source. Lactobacilli are claimed to provide a number of health benefits, including antimicrobial effects against pathogenic bacteria, antitumor effects, and protection against antibiotic- associated diarrhea or food allergy. Lactobacilli are reported to be acid and bile tolerant and survive in the tract.

The human colon is one of the body's most metabolically active organs. Gut bacteria predominantly ferment undigested food materials. This nature of fermentation may have different health consequences. There has been an increasing interest in use of diet to fortify certain gut flora. In this context, probiotics and prebiotics play significant roles. 
Probiotics are live microorganisms, which when added to foods help restore gut flora of the host. The term prebiotics, which is "a nondigestible food ingredient that beneficially affects the host by selectively stimulating the growth and activity of one or a limited number of bacteria in the colon". Symbiotic are the combination of both approaches.

There has been a considerable interest in the use of prebiotics to enhance the survival and colonization of probiotics bacteria that are added in food (Desai et al., 2003). A range of oligosaccharides has been tested using various methods to assess their prebiotics effect. Some research with prebiotics has shown reductions in putative risk factors for colon cancer and control of serum triglycerides and cholesterol.

Lactobacilli have been used widely in dairy products because of their health-promoting effects. Although the effect of oligosaccharides on colonic Lactobacilli has not been studied widely, there are reports on the effects of oligosaccharides on Lactobacilli in general.

According to the American Dietetic Association, fibers improve the intestinal functions, reduce blood pressure, can help control weight and improve serum cholesterol levels. Furthermore, the fibers that have prebiotics effects stimulate the bacteria existing in the colon, fact that has a beneficial influence on the health of the host.

Keeping this finding in mind, present investigation was carried out for improvement in the functionality and the viability of probiotics bacteria Lactobacillus casei spp. in fermented milk by adding oat brawn and buckwheat flour, rich in bioactive compounds, with prebiotics and protective effects. Survival of Lactobacilli in prebiotics was strain specific, but in general their survival was enhanced (Vasile, 2011).

\section{Materials and Methods}

\section{Chemicals}

All chemicals were used from Merck and Himedia.

\section{Probiotic lactic acid bacteria}

Lactobacillus casei was isolated from the milk samples of MGM college dairy milk by spread plate and streak plate method, to get pure culture, these were sub cultured 3 times on MRS broth at $37^{\circ} \mathrm{C}$ for $24 \mathrm{hrs}$ and maintain. Also commercial culture was used as standard. The storage and maintenance of the culture was carried out as per the recommendation of the manufacturer.

\section{Vegetal substrates}

Buckwheat flour (Fagopyrum esculentum) and oat bran (Avena sativa) were purchased from a market of Aurangabad (MS) India.

\section{Experimental site}

The experiment was conducted in the Department of Post-Harvest and Food Biotechnology of MGM College of Agriculture Biotechnology, Aurangabad (MS) India.

\section{Experimental Details}

Statistical design: Completely Randomized Designs (CRD).

No. of treatments: 21

Total No. of Replication: 3

\section{Gram staining}

The isolated bacteria were examined by using gram staining technique. To accomplish this, overnight grown suspension culture loopful of 
Lactobacillus was taken on slide and prepare smear and allow to air dry. Fixing was done by heating on spirit lamp. To stain, crystal violet was added by using dropper and incubates it up to $1 \mathrm{~min}$. Wash with gentle flow of tap water. Then grams iodine added for 1 min and wash again with tap water and $70 \%$ ethanol, follow repeat wash with tap water. At last saffranin was added and kept up to 3 min. Final wash was given with tap water and air dry the slide, prepared slide was further observe under oil emersion objective.

\section{Catalase test}

To perform this test, a single isolated colony was streaked on a glass slide and one drop of 3 $\%$ hydrogen peroxide (Merck, Germany) was added on to it. The effervescence of oxygen indicated the positive response of the bacteria to catalase test (Nelson et al., 1995).

\section{Preparation of pre and probiotics}

For the preparation and isolation of probiotics MRS media was used for the growth of Lactobacillus spp. which was isolated from curd and also commercial culture of Lactobacilli casei grown and maintain at proper condition. Both isolated and commercial culture was subjected for the cell viability as well as cell survival test.

\section{Fermented milk sample preparation}

Each sample has been obtained from $10 \mathrm{ml}$ inoculum with 11 Colony Forming Units (CFU)/ of L. casei, 90 UHT milk (3.5\% fat) in which were added 5\% (w/v), 9\% (w/v) and $13 \%(w / v)$ maize and oat flour respectively (Vasile 2011). A control sample without added vegetal substrate was prepared in the same conditions. The fermentation was conducted at $37^{\circ} \mathrm{C}$ until a value of $\mathrm{pH}$ 4.6. After fermentation, all samples were stored at $4^{\circ} \mathrm{C}$ for 21 days.

\section{Probiotics bacteria counting}

Viable cell counts were determined by preparing serial decimal dilutions with $0.1 \%$ $(\mathrm{w} / \mathrm{v})$ peptone water (Merck) which were subsequently plated on MRS agar (Merck) on Petri dishes. The plates were incubated at anaerobic for $48 \mathrm{hrs}$, at $37^{\circ} \mathrm{C}$. Plates containing 25-250 colonies were selected and $\mathrm{CFU} /$ fermented product were recorded. All plate counts were carried out in duplicates.

\section{Cells viability testing}

Simulated gastric juice (SGJ) consisted of 9 $\mathrm{g} / \mathrm{L}$ of sodium chloride containing $3.0 \mathrm{~g} / \mathrm{L}$ of pepsin with $\mathrm{pH}$ adjusted to 2.0 with hydrochloric acid. Since the probiotics fermented milk products have a shelf life of 21 days, it was decided to evaluate the cell viability after an average storage of 14 days.

After 14 days of storage, 0.2 fermented milk have been taken and homogenized with 10 of simulated gastric juice and incubated for 30 , 60 and 90 minutes respectively at $37^{\circ} \mathrm{C}$.

Surviving bacteria were counted by pour plate techniques in MRS agar by anaerobic incubation at $37^{\circ} \mathrm{C}$, for 3 days, according to the methods described by Chavari et al., (2010). The data is expressed as means from three independent experiments with two replicates.

\section{Results and Discussion}

\section{Gram staining}

The isolated bacteria were observed by light microscope. It is clear that the bacteria was gram positive, rod shaped coccobacilli, occurring singly or in chains. The gram staining results indicated that the isolated bacteria could be identified as Lactobacilli (Holt et al., 1994). 


\section{Catalase test}

The catalase test is one of the most useful diagnostic tests for the recognition of bacteria due to their simplicity. In performing catalase test, no bubble was observed indicating that the isolated bacterium was catalase negative and could not mediate the decomposition of $\mathrm{H}_{2} \mathrm{O}_{2}$ to produce $\mathrm{O}_{2}$. It is well known that Lactobacillus acidophilus is catalase negative (Schillinger 1999; Robinson 1990).

\section{Fermented milk sample preparation}

After fermentation, all samples were stored at $4^{\circ} \mathrm{C}$ for 21 days. After 21 days all samples are ready to evalution of probiotics bacteria counting and cell viability test (Plate. 1 ).

\section{Evaluation of probiotic bacteria counting}

To have probiotics effect, the probiotics strains have to be present in the final product in a sufficiently high number.

The treatments were analysed statistically by using the statistical design CRD with 3 replication (Panse and Sukhatme, 1967). The differences in the no. of colonies of different treatments were found significant (Fig. 1).

At $5 \%$ oat was at par with $9 \%$ oat and $5 \%$ maize (Plate 2) and found significantly superior over rest of others and indicating that Lactobacilli grown on milk added with prebiotics such as 5\% oat, 9\% oat and 5\% maize gives good growth. Thus $5 \%$ oat, $9 \%$ oat as well as $5 \%$ maize is favourable prebiotics for the growth of Lactobacilli.

At $9 \%$ oat was at par with $5 \%$ maize and $9 \%$ Maize and found significantly superior over T3, T7 and T6 indicating that Lactobacilli grown on milk added with prebiotics such as 9\% Oat, 5\% maize and 9\% maize gives good growth.
At 5\% maize was at par with $9 \%$ maize and $13 \%$ oat and significantly superior over $\mathrm{T} 7$ and T6 indicating that Lactobacilli grown on milk added with prebiotics such as 5\% maize, $9 \%$ maize and $13 \%$ oat gives good growth. At $9 \%$ maize was at par with $13 \%$ oat and found significantly superior over $\mathrm{T} 7$ and $\mathrm{T} 6$ indicating that Lactobacilli grown on milk added with prebiotics such as $9 \%$ Maize and $13 \%$ oat gives good growth.

At $13 \%$ oat was at par with control (without prebiotic) and $13 \%$ maize indicating that Lactobacilli grown on milk added with prebiotics such as $13 \%$ oat, control and $13 \%$ maize gives good growth. The control (without prebiotics) treatments was at par with $13 \%$ maize found to be most inferior treatment among all the treatments. This indicates that when Lactobacilli cells were grown as control and $13 \%$ maize show very less no of colonies were found. This might be due to the absence of prebiotics and unfavourable for the growth of Lactobacilli (Table 1).

\section{Evaluation of cells viability testing}

Taking into account the results previously presented, the survival in simulated gastric juice of the L. casei, after 14 days of storage of fermented products has been analyzed (Aghajani et al., 2012; Kawther et al., 2010). The treatments were analysed statistically by using the statistical design CRD with 3 replication. The differences in the no. of colonies of different treatments were found significant (Table 2).

At $5 \%$ maize was at par with $9 \%$ oat and found significantly superior over rest of others indicating that Lactobacilli grown on milk added with prebiotics such as $5 \%$ maize and 9\% oat give good growth when exposed to gastric juice for $30 \mathrm{~min}$ and $30 \mathrm{~min}$. Thus $5 \%$ maize as well as $9 \%$ oat is favourable prebiotics for the growth of Lactobacilli. 
Int.J.Curr.Microbiol.App.Sci (2018) 7(11): 1311-1321

Plate.1 Fermented samples of oat and maize

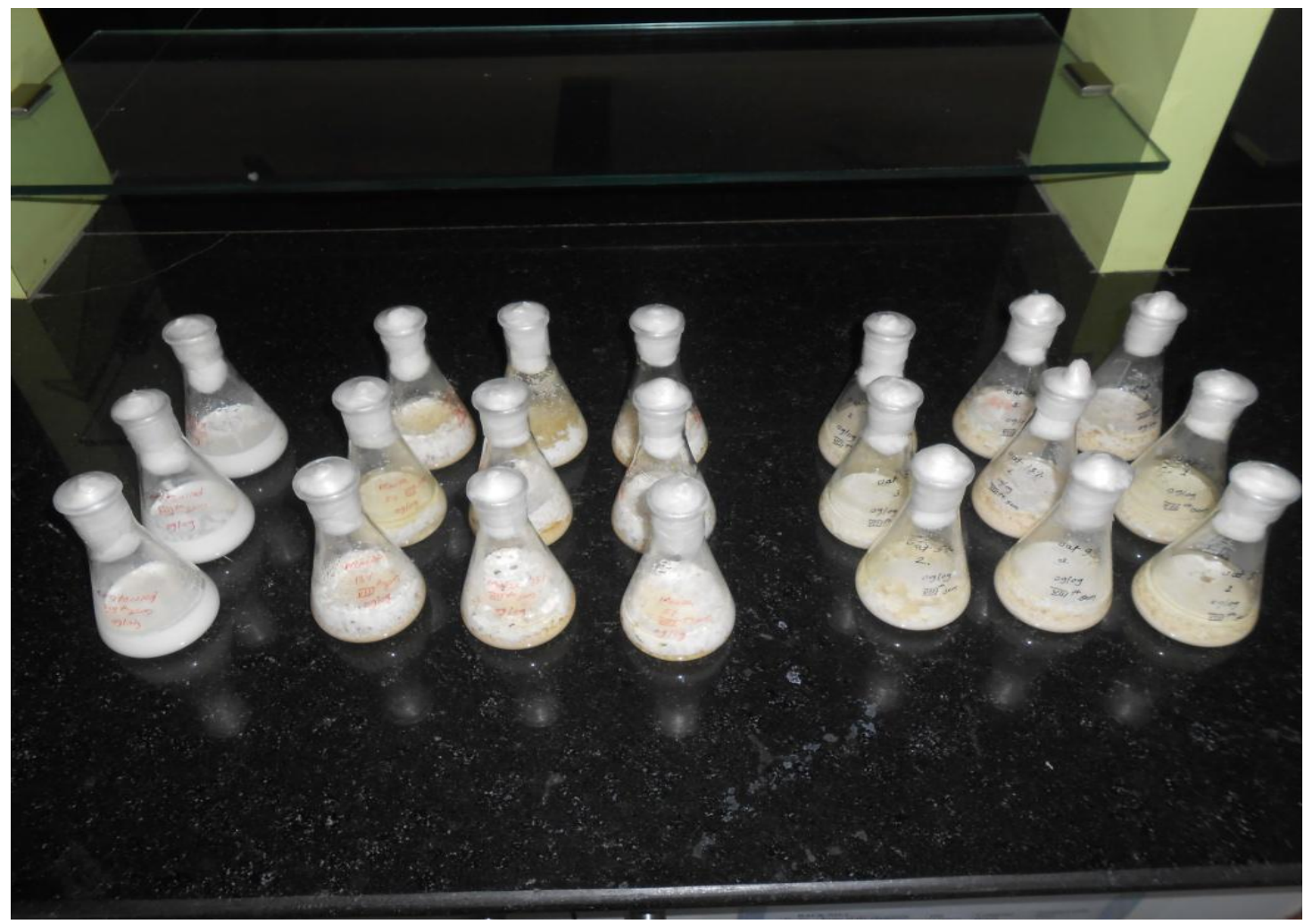

Plate.2 Colonies of probiotics bacteria grown on $5 \%$ oat

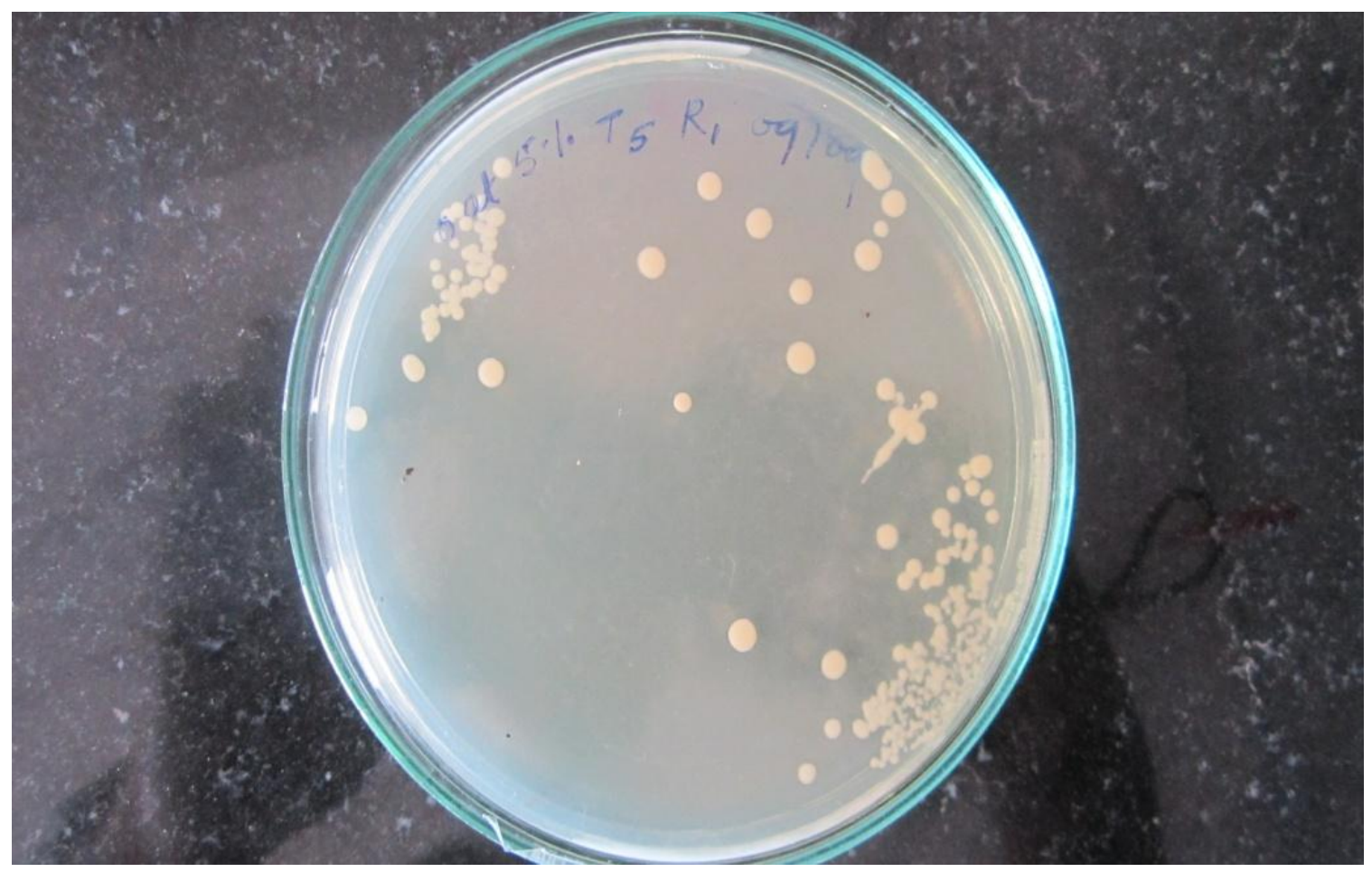


Plate.3 Colonies of probiotics bacteria grown on $9 \%$ oat exposed to gastric juice for 60 min

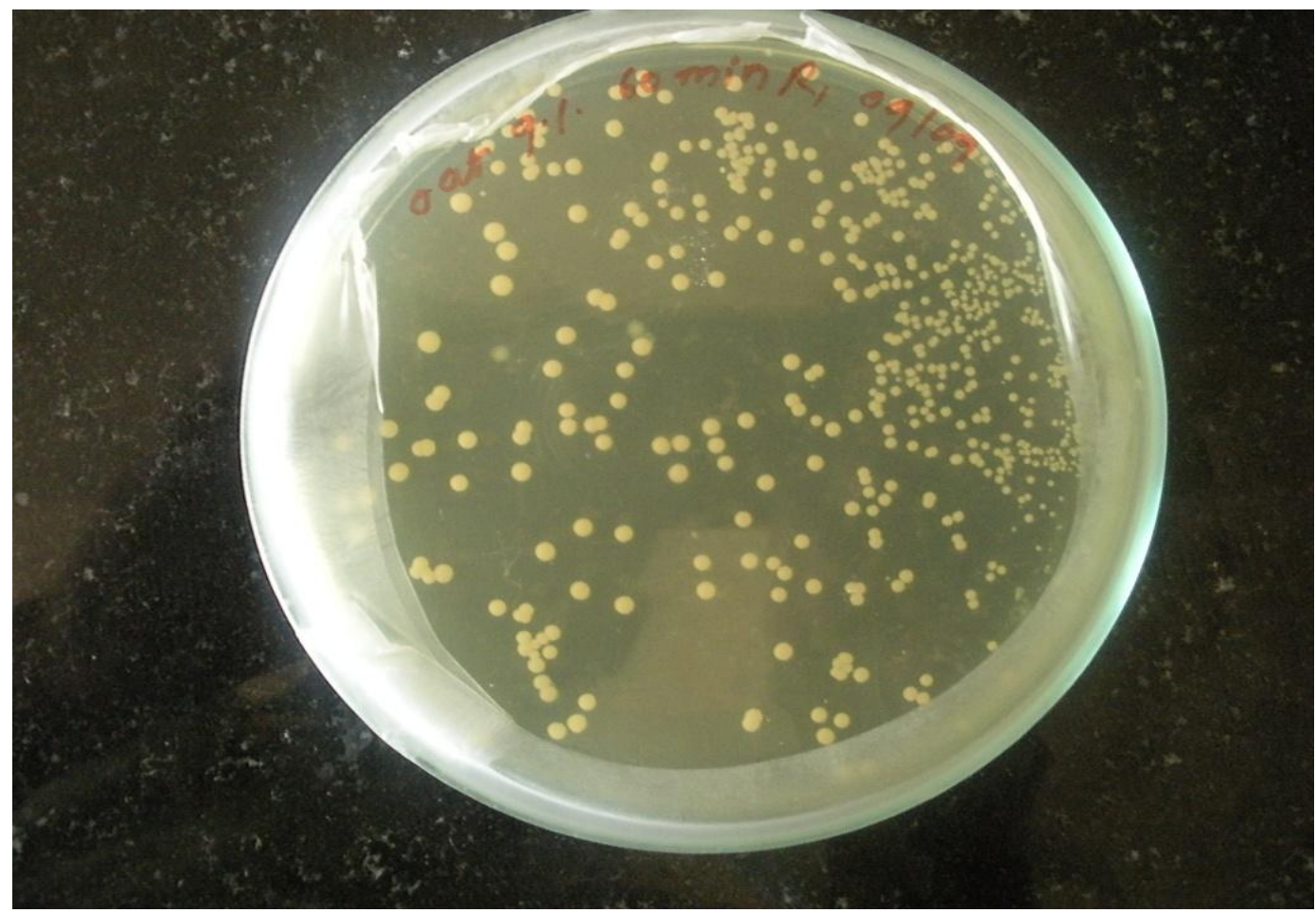

Plate.4 Colonies of probiotics bacteria grown on $9 \%$ maize exposed to gastric juice for 30 min

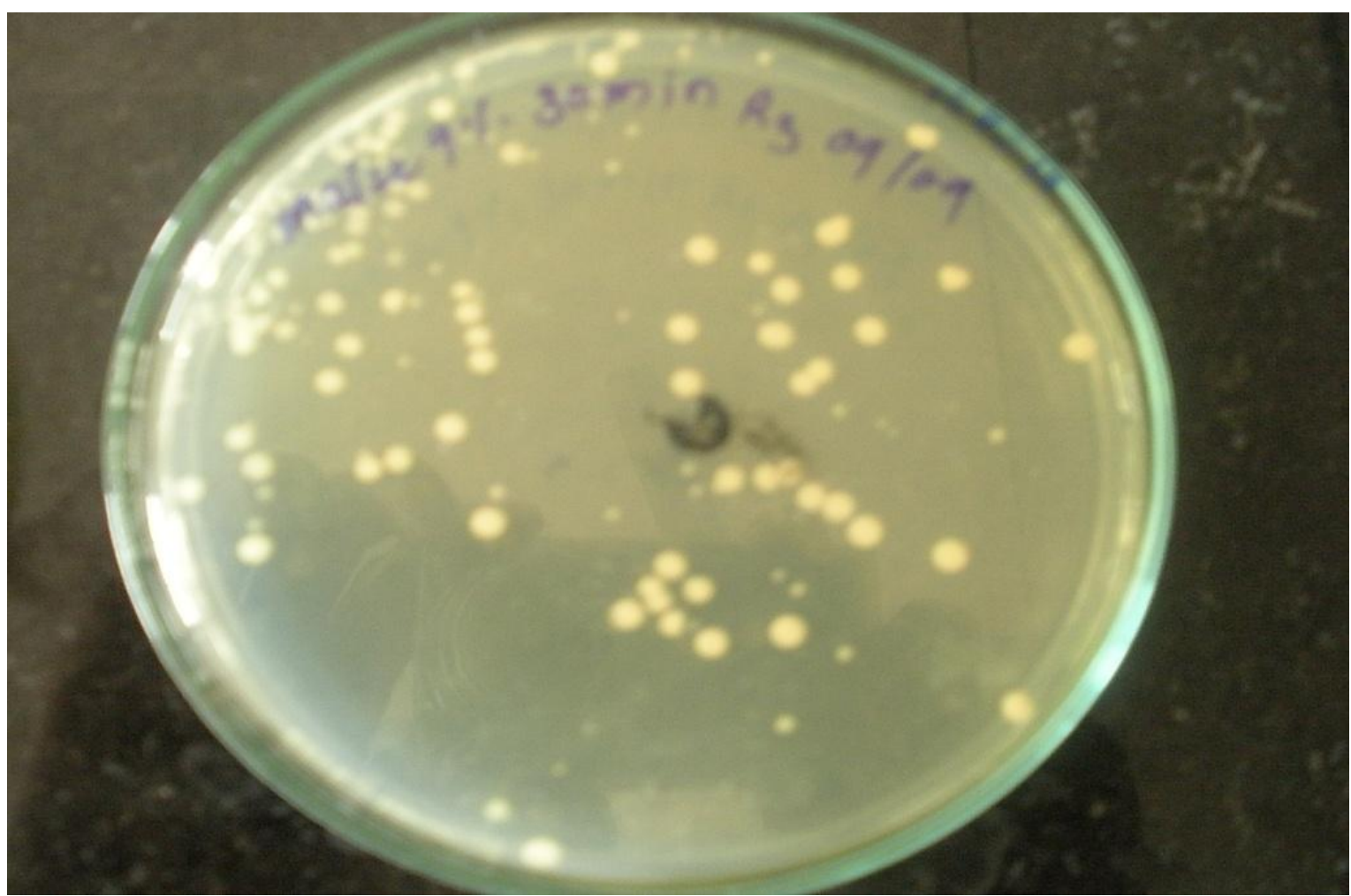


Fig.1 Enhance of the $L$. casei bacterial count in fermented milk with added different percentage of maize and oat prebiotics

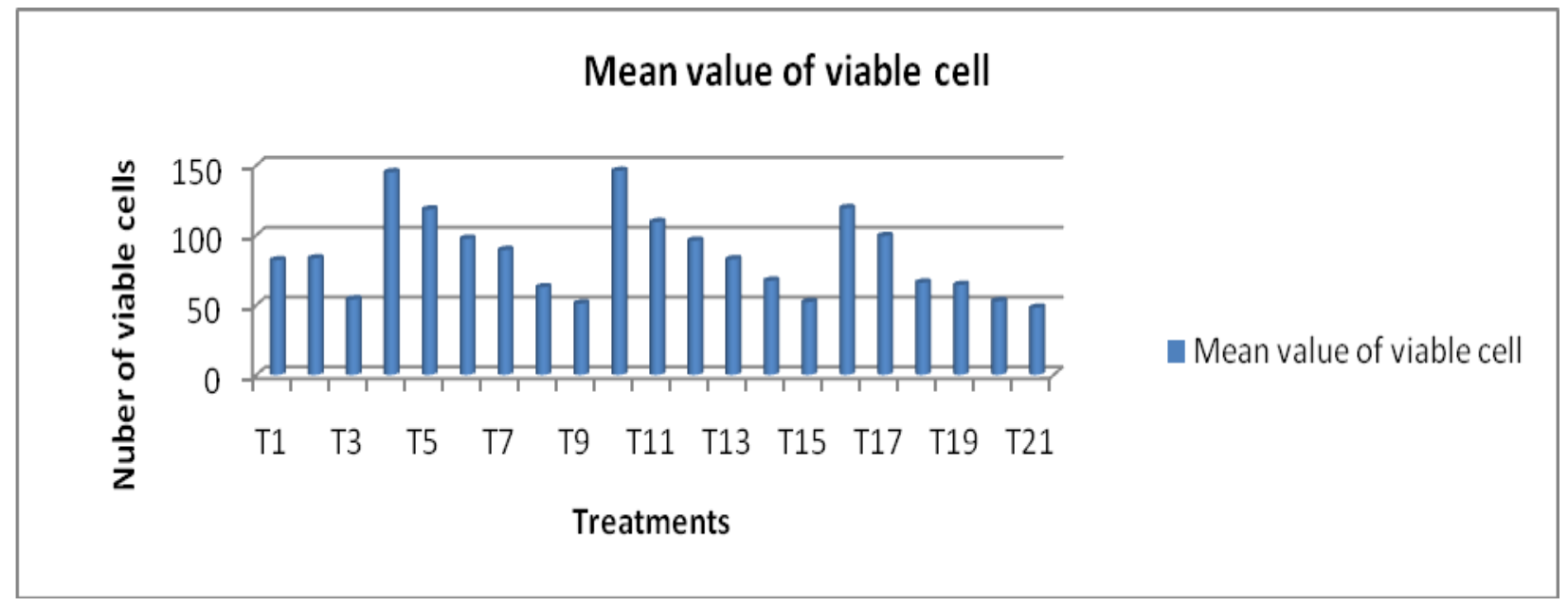

Fig.2 Enhance of the L. casei cell viability in fermented milk with added different percentage of maize and oat prebiotics

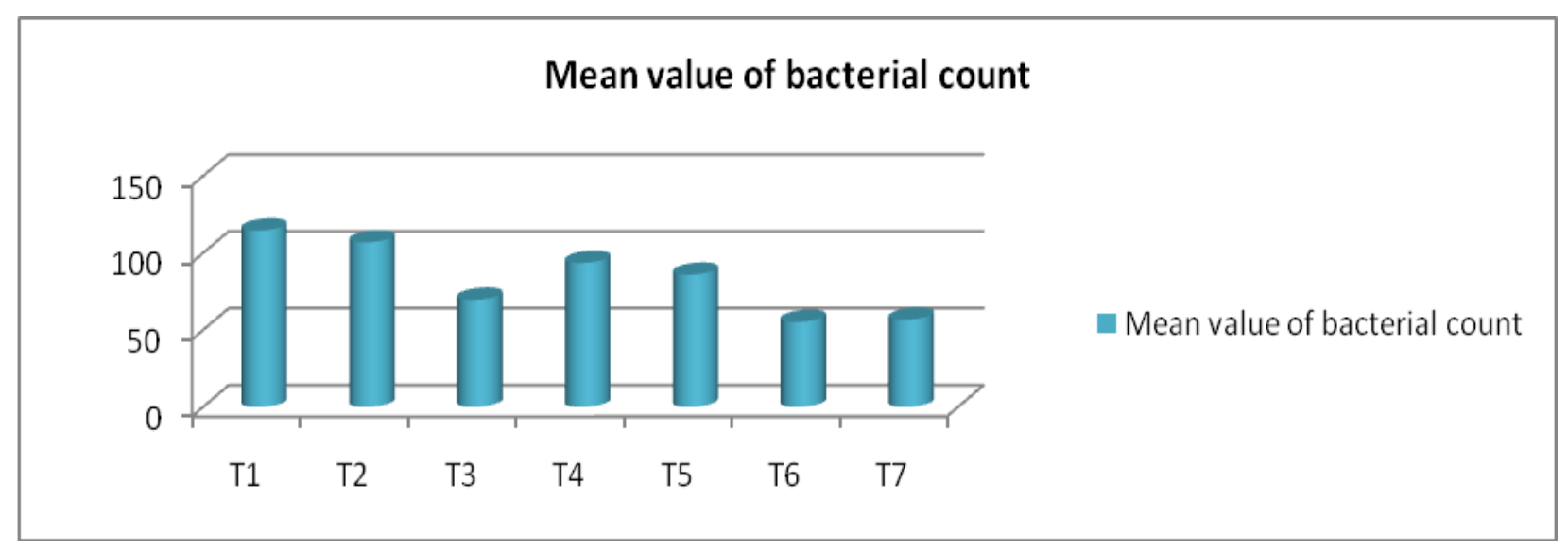

Table.1 Mean values of probiotics bacteria counting

\begin{tabular}{|c|c|}
\hline Treatments & MEAN \\
\hline T1 5 \% Oat & 114.67 \\
\hline T2 9\% Oat & 107.00 \\
\hline T3 13\% Oat & 69.67 \\
\hline T4 5 M Maize & 93.67 \\
\hline T5 $\%$ Maize & 86.00 \\
\hline T6 13\% Maize & 55.33 \\
\hline T7 Control (without prebiotics) & 56.67 \\
\hline
\end{tabular}

SEm. $=9.94$

CD. (0.05) $=28.72$ 
Table.2 Mean value of cell viability test

\begin{tabular}{|c|c|}
\hline Replication-and Treatments & MEAN \\
\hline T1 (5\% Oat30 Min) & $\mathbf{8 2 . 0 0}$ \\
\hline T2 (5\% Oat60 Min) & 83.33 \\
\hline T3 (5\% Oat90 Min) & $\mathbf{5 4 . 0 0}$ \\
\hline T4 (9\% Oat 30 Min) & 145.00 \\
\hline T5 (9\% Oat 60 Min) & 118.33 \\
\hline T6 (9\% Oat 90 Min) & 97.33 \\
\hline T7 (13\% Oat 30 Min) & $\mathbf{8 9 . 3 3}$ \\
\hline T8 (13\% Oat 60 Min) & 62.67 \\
\hline T9 (13\% Oat 90 Min) & $\mathbf{5 1 . 0 0}$ \\
\hline T10 (5\% Maize30 Min) & 146.00 \\
\hline T11 (5\% Maize60 Min) & 109.33 \\
\hline T12 (5\% Maize90 Min) & 96.00 \\
\hline T13 (9\% Maize30 Min) & $\mathbf{8 2 . 6 7}$ \\
\hline T14 (9\% Maize60 Min) & 67.33 \\
\hline T15 (9\% Maize90 Min) & $\mathbf{5 2 . 0 0}$ \\
\hline T16 (13\% Maize30Min) & $\mathbf{1 1 9 . 3 3}$ \\
\hline T17 (13\% Maize60 Min) & 99.33 \\
\hline T18 (13\% Maize90 Min) & 66.00 \\
\hline T19 (Control 30Min) & 64.33 \\
\hline T20(Control 60 Min) & $\mathbf{5 2 . 6 7}$ \\
\hline T21(Control 90 Min) & 48.00 \\
\hline
\end{tabular}

SEm. $=6.896$

CD. $(0.05)=19.502$

\section{Experimental Details}

\begin{tabular}{|c|c|}
\hline Treatment & Addition of prebiotics \\
\hline $\mathrm{T} 1$ & $5 \%$ Oat $30 \mathrm{Min}$ \\
\hline $\mathrm{T} 2$ & $5 \%$ Oat $60 \mathrm{Min}$ \\
\hline $\mathrm{T} 3$ & $5 \%$ Oat $90 \mathrm{Min}$ \\
\hline $\mathrm{T} 4$ & $9 \%$ Oat $30 \mathrm{Min}$ \\
\hline $\mathrm{T} 5$ & $9 \%$ Oat $60 \mathrm{Min}$ \\
\hline $\mathrm{T} 6$ & $9 \%$ Oat $90 \mathrm{Min}$ \\
\hline $\mathrm{T} 7$ & $13 \%$ Oat $30 \mathrm{Min}$ \\
\hline $\mathrm{T} 8$ & $13 \%$ Oat $60 \mathrm{Min}$ \\
\hline $\mathrm{T} 9$ & $13 \%$ Oat $90 \mathrm{Min}$ \\
\hline $\mathrm{T} 10$ & $5 \%$ Maize $30 \mathrm{Min}$ \\
\hline $\mathrm{T} 11$ & $5 \%$ Maize $60 \mathrm{Min}$ \\
\hline $\mathrm{T} 12$ & $5 \%$ Maize $90 \mathrm{Min}$ \\
\hline $\mathrm{T} 13$ & $9 \%$ Maize $30 \mathrm{Min}$ \\
\hline $\mathrm{T} 14$ & $9 \%$ Maize $60 \mathrm{Min}$ \\
\hline $\mathrm{T} 15$ & $9 \%$ Maize $90 \mathrm{Min}$ \\
\hline $\mathrm{T} 16$ & $13 \%$ Maize $30 \mathrm{Min}$ \\
\hline $\mathrm{T} 17$ & $13 \%$ Maize $60 \mathrm{Min}$ \\
\hline $\mathrm{T} 18$ & $13 \%$ Maize $90 \mathrm{Min}$ \\
\hline $\mathrm{T} 19$ & Control 30 Min \\
\hline $\mathrm{T} 20$ & Control $60 \mathrm{Min}$ \\
\hline $\mathrm{T} 21$ & Control $90 \mathrm{Min}$ \\
\hline
\end{tabular}


At $13 \%$ maize was at par with $9 \%$ oat and $5 \%$ maize and found significantly superior over T17, T6, T12, T7, T2, T13, T1, T14, T18, T19, T8, T3, T20, T15, T9 and T21 indicating that Lactobacilli grown on milk added with prebiotics such as $13 \%$ maize, $9 \%$ oat and $5 \%$ maize give good growth when exposed to gastric juice for $30 \mathrm{~min}, 60 \mathrm{~min}$ and $60 \mathrm{~min}$ respectively.

At $9 \%$ oat was at par with $5 \%$ maize and $13 \%$ maize and found significantly superior over T6, T12, T7, T2, T13, T1, T14, T18, T19, T8, T3, T20, T15, T9 and T21 over indicating that Lactobacilli grown on milk added with prebiotics such as $9 \%$ oat, $5 \%$ maize and $13 \%$ maize give good growth when exposed to gastric juice for $60 \mathrm{~min}, 60 \mathrm{~min}$ and $60 \mathrm{~min}$ respectively.

At $5 \%$ maize was at par with $13 \%$ maize, $9 \%$ oat and $5 \%$ and found significantly superior over T7, T2, T13, T1, T14, T18, T19, T8, T3, T20, T15, T9 and T21 indicating that Lactobacilli grown on milk added with prebiotics such as 5\% maize, $13 \%$ maize, $9 \%$ oat and 5\% maize give good growth when exposed to Gastric juice for $60 \mathrm{~min}, 60 \mathrm{~min}$, $90 \mathrm{~min}$ and $90 \mathrm{~min}$ respectively.

At $13 \%$ maize was at par with $9 \%$ oat and $5 \%$ maize, $13 \%$ oat, $5 \%$ oat $9 \%$ maize and $5 \%$ oat and found significantly superior found over T14, T18, T19, T8, T3, T20, T15, T9 and T21 indicating that Lactobacilli grown on milk added with prebiotics such as $13 \%$ maize, $9 \%$ oat and $5 \%$ maize, $13 \%$ oat, $5 \%$ oat $9 \%$ maize and $5 \%$ oat give good growth when exposed to gastric juice for $60 \mathrm{~min}, 90 \mathrm{~min}, 90 \mathrm{~min}, 30$ min, $60 \mathrm{~min}, 30 \mathrm{~min}$ and $30 \mathrm{~min}$ respectively.

At $9 \%$ oat was at par with $5 \%$ maize, $13 \%$ oat, $5 \%$ oat, $9 \%$ maize, $5 \%$ oat and found significantly superior over T14, T18, T19, T8, T3, T20, T15, T9 and T21 indicating that Lactobacilli grown on milk added with prebiotics such as $9 \%$ oat, $5 \%$ maize, $13 \%$ oat, $5 \%$ oat, $9 \%$ maize, $5 \%$ oat give good growth when exposed to gastric juice for 90 min, $90 \mathrm{~min}, 30 \mathrm{~min}, 60 \mathrm{~min}, 30 \mathrm{~min}$ and 30 min respectively.

At $5 \%$ maize was at par with $13 \%$ oat, $5 \%$ oat, $9 \%$ maize and $5 \%$ oat and found significantly superior over T14, T18, T19, T8, T3, T20, T15, T9 and T21 indicating that Lactobacilli grown on milk added with prebiotics such as 5\% maize, $13 \%$ oat, 5\% oat, $9 \%$ maize and $5 \%$ oat give good growth when exposed to gastric juice for $90 \mathrm{~min}, 30$ min, $60 \mathrm{~min}, 30 \mathrm{~min}$ and $30 \mathrm{~min}$ respectively.

At $13 \%$ oat was at par with $5 \%$ oat, $9 \%$ maize and $5 \%$ oat and found significantly superior over T14, T18, T19, T8, T3, T20, T15, T9 and T21 indicating that Lactobacilli grown on milk added with prebiotics such as $13 \%$ oat, $5 \%$ oat, $9 \%$ maize and $5 \%$ oat give good growth when exposed to gastric juice for 30 min, $60 \mathrm{~min}, 30 \mathrm{~min}$ and $30 \mathrm{~min}$ respectively.

At $5 \%$ oat was at par with $9 \%$ maize and $5 \%$ oat and found significantly superior over T14, T18, T19, T8, T3, T20, T15, T9 and T21 indicating that Lactobacilli grown on milk added with prebiotics such as 5\% oat, $9 \%$ maize and $5 \%$ oat give good growth when exposed to Gastric juice for $60 \mathrm{~min}, 30 \mathrm{~min}$ and $30 \mathrm{~min}$.

At $9 \%$ maize was at par with $5 \%$ oat, $9 \%$ maize, $13 \%$ maize and control and found significantly superior over T8, T3, T20, T15, T9 and T21 indicating that Lactobacilli grown on milk added with prebiotics such as $9 \%$ maize, $5 \%$ oat, $9 \%$ maize, $13 \%$ maize and control give good growth when exposed to gastric juice for $30 \mathrm{~min}, 60 \mathrm{~min}, 90 \mathrm{~min}, 30$ min respectively.

At $5 \%$ oat was at par with $9 \%$ maize, $13 \%$ maize and control and found significantly 
superior over T8, T3, T20, T15, T9 and T21 indicating that Lactobacilli grown on milk added with prebiotics such as 5\% oat, 9\% maize, $13 \%$ maize and control give good growth when exposed to gastric juice for 30 min, $60 \mathrm{~min}, 90 \mathrm{~min}$, and $30 \mathrm{~min}$ respectively.

At $9 \%$ maize was at par with $13 \%$ maize, control, $13 \%$ oat, $5 \%$ oat, control, $9 \%$ maize, $13 \%$ oat and control indicating that Lactobacilli grown on milk added with prebiotics such as 9\% maize, $13 \%$ maize, control, $13 \%$ oat, $5 \%$ oat, control, $9 \%$ maize, $13 \%$ oat and control give good growth when exposed to gastric juice for $60 \mathrm{~min}, 90 \mathrm{~min}$, $30 \mathrm{~min}, 60 \mathrm{~min}, 90 \mathrm{~min}, 60 \mathrm{~min}, 90 \mathrm{~min}, 90$ min and 90 min respectively.

At $13 \%$ maize was at par with control, $13 \%$ oat, $5 \%$ oat, control, $9 \%$ maize, $13 \%$ oat and control indicating that Lactobacilli grown on milk added with prebiotics such as $13 \%$ maize, control, $13 \%$ oat, $5 \%$ oat, control, $9 \%$ maize, $13 \%$ oat and control give good growth when exposed to gastric juice for $90 \mathrm{~min}, 30$ min, $60 \mathrm{~min}, 90 \mathrm{~min}, 60 \mathrm{~min}, 90 \mathrm{~min}, 90 \mathrm{~min}$ and 90 min respectively.

The control was at par with $13 \%$ oat, $5 \%$ oat, control, 9\% maize, $13 \%$ oat and control indicating that Lactobacilli grown on milk added with prebiotics such as control, $13 \%$ oat, $5 \%$ oat, control, $9 \%$ maize, $13 \%$ oat and control give good growth when exposed to gastric juice for $30 \mathrm{~min}, 60 \mathrm{~min}, 90 \mathrm{~min}, 60$ min, $90 \mathrm{~min}, 90 \mathrm{~min}$ and $90 \mathrm{~min}$ respectively.

At $13 \%$ oat was at par with $5 \%$ oat, control, 9\% maize, $13 \%$ oat and control indicating that Lactobacilli grown on milk added with prebiotics such as $13 \%$ oat, $5 \%$ oat, control, 9\% maize, $13 \%$ oat and control give good growth when exposed to gastric juice for 60 min, $90 \mathrm{~min}, 60 \mathrm{~min}, 90 \mathrm{~min}, 90 \mathrm{~min}$ and 90 min respectively. At 5\% oat was at par with control, 9\% maize, $13 \%$ oat and control indicating that Lactobacilli grown on milk added with prebiotics such as $5 \%$ oat, control, $9 \%$ maize, $13 \%$ oat and control give good growth when exposed to gastric juice for 90 min, $60 \mathrm{~min}, 90 \mathrm{~min}, 90 \mathrm{~min}$ and $90 \mathrm{~min}$ respectively.

The control was at par with 9\% maize, 13\% oat and control indicating that Lactobacilli grown on milk added with prebiotics such as control, 9\% maize, $13 \%$ oat and control give good growth when exposed to gastric juice for $60 \mathrm{~min}, 90 \mathrm{~min}, 90 \mathrm{~min}$ and $90 \mathrm{~min}$ respectively.

At $9 \%$ maize was at par with $13 \%$ oat and control indicating that Lactobacilli grown on milk added with prebiotics such as $9 \%$ maize, $13 \%$ oat and control give good growth when exposed to gastric juice for $90 \mathrm{~min}, 90 \mathrm{~min}$ and $90 \mathrm{~min}$ respectively.

At $13 \%$ oat and control was found to be most inferior treatment among all the treatments. This indicates that when Lactobacilli cells were exposed to $13 \%$ oat and control and exposed to gastric juice for $90 \mathrm{~min}$ and 90 min respectively, very less no. Of colonies were found. This might be due to the very high concentration of oat bran and high exposure time to gastric juice which become unfavourable for the growth of Lactobacilli. Our results are in good agreement with those reported by Guergoletto et al., (2010).

Among the two prebiotics used the Lactobacilli grown with maize showed significant viability with higher no. of colonies. Similarly these Lactobacilli cells remain viable (Akalin et al., 2002) even after exposing to gastric juice of $\mathrm{pH}-(2.0)$. The Lactobacilli which were grown with the addition of Oat bran also showed enhanced activity but as compare to maize they showed less viability when exposed to gastric juice (Plate 3, 4 and Fig. 2). 


\section{References}

Aghajani A.R., Pourahmad R. and Mahdavi Adeli H.R. 2012. Evaluation of Physicochemical Changes and Survival of Probiotic Bacteria in Synbiotic Yoghurt. Journal of Food Biosciences and Technology. 02: 13-22.

Akalin A. S., Fenderya S. and Akbulut N. 200 2. Viability and activity of bifidobacteri a in yoghurt containing fructo oligosaccharide during refrigerated storage. Int $\mathrm{J}$. of Food Science and Technology, 39(6): 613-621.

Desai A.R., Powell I.B., And Shah N.P. 2003. Survival and Activity of Probiotic Lactobacilli in Skim Milk Containing Prebiotics. School of Biomedical and Health Science. 57-60.

Holt G, Krieg N, Sneath P, Staley J, Williams S. Bergey's Manual of Determinative of Bacteriology. 9th edition. Williams and Wilkins. USA, 1994: 560-570.

Kawther, Shafei E.L., Tawfik N.F., Nadia, Dabiza M.A., Sharaf O.M., and Effat B.A. 2010. In vitro assessment of gastrointestinal viability of potentially probiotic Lactobacilli. J. of American Science. 6. 01-11.

Nelson, G. and George, S. Comparison of media for selection and enumeration of mouse fecal flora populations. J. Microbiol. Methods 1995; 22: 293-300.

Panse V.G. and Sukhatme P.V. 1967. Statistical methods for Agricultural Workers. 2 edition. ICAR Publications. New Delhi. 381.

Robinson R: Dairy Microbiology Volume (1) The microbiology of milk. 2nd edn., Elsevier science publishing Co. INC. USA. 1990

Schillinger U. Isolation and identification of Lactobacilli from novel-type probiotic and mild yoghurts and their stability during refrigerated storage. International Journal of Food Microbiology1999; 47: 79-87.

Vasile. A., Daniela. P., Stefan, D. and Gabriela, B. 2011. Growth and cell viability improve of the probiotic strain Lactobacillus casei ssp. paracasei in the presence of oat bran and buckwheat flour. Innovative Romanian Food Biotechnology. 09: 52-59.

\section{How to cite this article:}

Chungada, A.S., K.G. Deshpande and Thakre, R.A. 2018. Pursuance of Skim Milk Containing Prebiotics on Survival and Activity of Probiotics Lactobacilli Bacteria. Int.J.Curr.Microbiol.App.Sci. 7(11): 1311-1321. doi: https://doi.org/10.20546/ijcmas.2018.711.152 